\title{
An applicable model for establishing sustainable traffic
}

\author{
Z. Vogrin, J. Golubić \& J. Golubić \\ Faculty of Transport and Traffic Sciences, University of Zagreb, Croatia
}

\begin{abstract}
Solving transport problems in the cities assumes the implementation of regulatory measures and a complex of technological, operational and economic measures. The improvement of transport conditions in urban areas is a precondition for their sustainable development. Regulative harmonization and regional infrastructure development is a necessary precondition in the integration process and in adopting the best practices in the organization of local (urban) transport. This paper deals with the problems of modelling urban public transport with regard to the principle of the sustainability of transport development, which integrates the objectives of mobility, physical planning and environmental protection in transport policy. The models for the improvement of urban transport in the projects realized are analogously applicable at a regional level. This fact is of great importance for the regulatory harmonization, strategic planning and policy development of urban transport management in Croatia. Keywords: urban public transport, modelling, mobility, transport policy.
\end{abstract}

\section{Introduction}

The transport sector is one of the key factors of economic and social development, both from the aspect of revenues in GDP, as well as from the aspect of the basic needs of living in a modern society - the need for mobility. In the past, worldwide practice in both the public and private sectors was included in the management and financing of the transport infrastructure and services. However, the division of roles and functions varies greatly depending on time, countries and different modes of transport. These differences are the reflection of many influencing factors, such as the availability of technologies and change in the amount of necessary investments, the awareness and importance of systemic planning and management, resources of managerial and technical skills, the 
government's financial situation and budget circumstances, historic experiences and institutional heritage. The implementation of transport policy measures assumes the adoption of a transport strategy based on the development of a transport system strategy and branch strategies. In this sense urban public transport is an integral part of the urban and suburban transport and the implementation of transport policy measures for urban transport assumes the adoption of an adequate development strategy for urban transport. The solving of transport problems in the cities assumes the implementation of regulatory measures and a complex of technological, operational and economic measures. The improvement of transport conditions in urban areas is a precondition for their sustainable development. A transport policy should concentrate on the creation and maintenance of legal and regulatory framework in order to attract private operators and at the same time protect the interests of the poor, improve the environmental conditions and coordinate inter-sector activities.

At the governmental level, the alternative of having a minimally regulated private monopoly on strategies for transport should be considered; it could potentially expand the service and achieve reasonable operational efficiency, in accordance with the alternative of having a public monopoly, which could provide inadequate service with high budget costs. In order to reduce the risks to public assets in the case of concessions or privatization, the use of public information and transparency are of extreme importance. The introduction of competitiveness is in many cases the most important step in creating the conditions of greater efficiency both for the private and the public operators. Extremely specific features that directly address the role of the government and private sector in their development and management have affected the problems of transport development and especially those of the development of the transport infrastructure, in a similar way to other important infrastructure sectors such as the energy and water supply. At national and metropolitan levels, the transport infrastructure correlates closely with the spatial arrangement and has a high affect on the spatial structuring of the total economy. These are the fields of the highest government responsibility, which require pro-active planning together with adequate price and tax policies [1]. Transport activity, especially on roads, has substantial negative external effects, such as congestion, pollution and accidents, which are reflected with greater seriousness than the generated externals in other sectors directly in the structure of prices and charges. This means that government intervention in improving the allocation of financial resources is necessary. This paper deals with the problems of modelling urban public transport with regard to the principle of the sustainability of transport development, which is of great importance within urban management in Croatia.

\section{Organization of local public transport}

The strategic objective of local communities is to achieve a transport system configuration, which recognizes four vital dimensions: the transport dimension an adequate balance between public and private transport share in satisfying the needs of all the market segments, the ecological dimension - retaining the 
overall level of pollution caused by transport at an acceptable level, the economic dimension - the potential creation of new financial resources via the solutions of giving "value for money" and the capacity for inducing the desired behaviour (demand) of users through fair charging mechanisms (without discrimination) and finally, the social dimension - providing the citizens with a transport system which suits their needs.

Since it is difficult to achieve an ideal system when modelling an urban public transport system, the acceptable solution is also one of establishing certain compensations among these domains, in compliance with the socio-economic and cultural reality of every specific urban district, the conditioned political option and accompanying financial support as the result of the interaction between the local, regional, and national levels of interventions. The model is, therefore, functional at a strategic level of defining the objectives as a response to the individual and social interests of stakeholders. There is no option for an urban transport system marked by the bilateral agreements between the operators who tend towards the maximization of their own profit, without offering a network whose size and form also efficiently assure the acceptable economies for the users and the local environment.

The form of urban public transport organization is conditioned by the main variables at a tactical level, out of which the first three are internal and the last one is external in relation to the mobility system: the plurality of initiatives and the level of freedom on the market and entrepreneurship, the level of competition and incentives within the system, the level of technical competence of the complex network planners and the political and administrative organization of the country/region.

The basic division here is between the regime in which the initiative is taken by the operator and the one in which the initiative of creating the transport system is left to the authority. The advantage of the former model, articulated by the notion of market initiative, is that it actually allows active participation of the operators in the service design and the stimulation of improving the service and the consequence that the operator takes over the majority of planning and revenue risk. The revenue risks are, as a rule, related to patronage and price and the latter substantially influences the quality and adequacy of the service to the customers' needs, so it is very important to include the operator in the creation of an urban public transport system. The planning risks result from various sources - urban planning also raises the issue of mobility; road infrastructure planning denotes the quality of the public transport operative, plan realization may be of an advantage and the deficiencies of their realization can substantially disturb the mobility system.

Within the aforementioned entrepreneurial classification, two different regulatory regimes regarding the level of system competitiveness are distinguished - the deregulated (free competition) and the control (concessionary) regime, which is a form of limited competition. The former is a good example of a lack of a market initiative system, which is reduced or sometimes inexistent, of network integration and of coordination with a certain decline in the quality of the public transport system. 


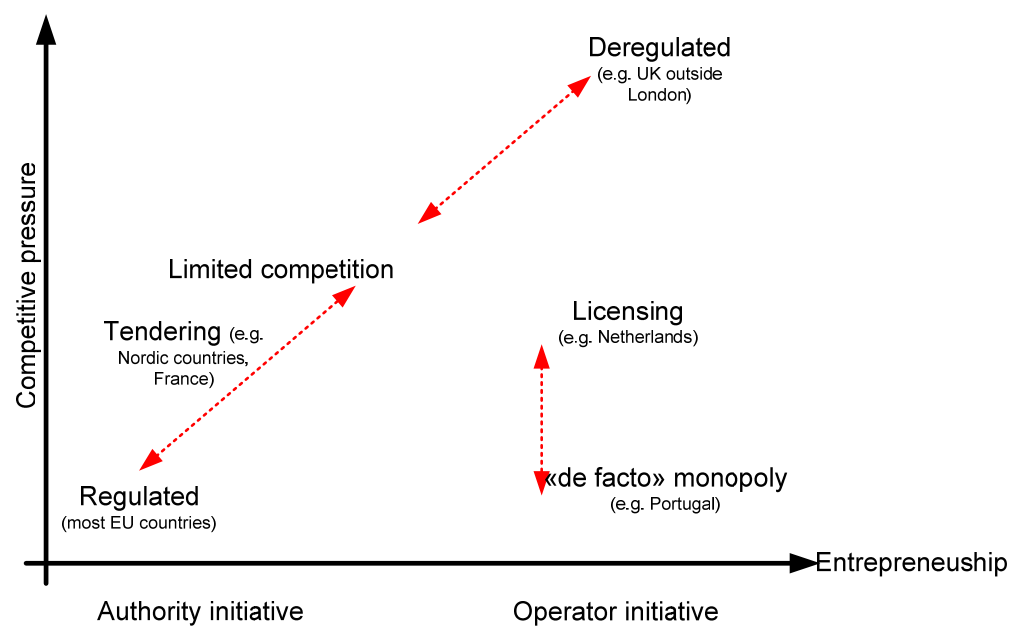

Figure 1: Classification of legal and regulatory regimes in Europe. Source: Macário [2].

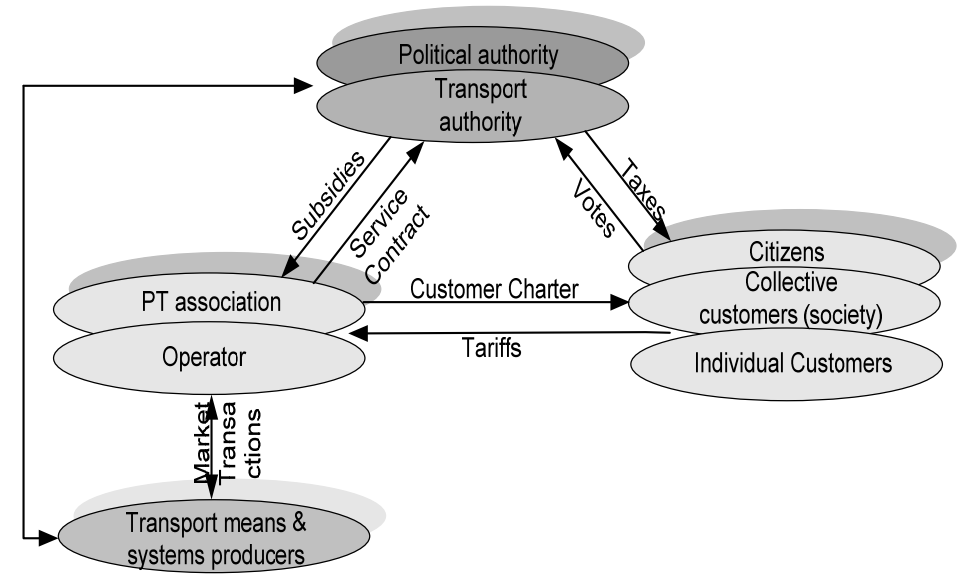

Figure 2: Conceptual simplified presentation of stakeholders' relationship. Source: MARETOPE [3].

In such systems of limited competition, management can alleviate the barriers by assigning concession, in order to satisfy the specific requirements of the system's integration (physical, tariff) and to achieve the balance between efficiency and consumption, i.e. allocate sources in compliance with the needs and preferences of the consumers and the operational efficiency. Where the 
creation of a public transport service is the responsibility of the authority, the satisfaction of strategic objectives is much easier to achieve in theoretical sense and the implementation must be possible at lower costs. The advantage of such a regime is in the structural priority of the integration and stability of serving whereas, cost-efficiency is achieved by other instruments. In these systems, the level of competition can vary depending on the alternative methods, applied by the management in achieving planned and productive values. In principle, the quality influences the consumers' satisfaction. In urban transport, apart from the users' satisfaction, the mobility system must also satisfy the political objectives, particularly the increase in the market share of public transport, the release of budget means and environmental protection. Therefore, urban public transport planning is functional in the coordination at all levels of decision-making, both in the conditions of the stable state regime and in the variable market environments. The management system is a unique and dynamic task and there is no specific recipe or recommendation for the best system. However, the main requirement in undertaking moderate changes in the system is the identification of those who will be affected by the changes and to what extent. In managing a system of urban mobility, there are four interdependent factors for successful change processes: the regulative and organizational regime of public transport services and other transportation services, the charging and financial regime of the public transport support, the integration of mobility policy, urban planning and environmental protection and an information technology system of support for managing urban mobility $[2,3]$.

Four groups of stakeholders can be considered, according to their potential for preventing changes to the system, as resisting carriers of their protected "status quo" positions: operators and associations of public transport, public management - political and transport, producers of transport means and systems and citizens/consumers.

Depending on these interrelations within the system of public transport, four basic organizational models can be also distinguished, which are traditionally accepted by the economic subjects - private and public - and which are used as the starting forms in analyses, since each of these models has a different relation to change. In the bureaucratic model, the organization is formed as a closed system, external factors do not influence the selections or strategies and management is determined strictly at the hierarchical basis. The organization focuses on realizing the procedures and the changes that are conditioned by the external factors are strictly rejected. In the technocratic model, the efficiency of introducing changes is higher, although the organization is still to a great extent based on procedures. The understanding and management of technological changes is the main objective in this model of organization and other categories of change remain as another priority.

In the managerial model, the reaction to market requirements is substantial, whereas the adjustment to changes is an instrument for achieving the primary objectives. The ideological model, typical of political and governing bodies, assesses changes on the basis of the effectiveness of political action, leaving the efficiency to be realized by other mechanisms. 


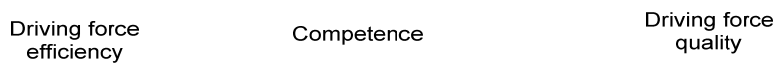

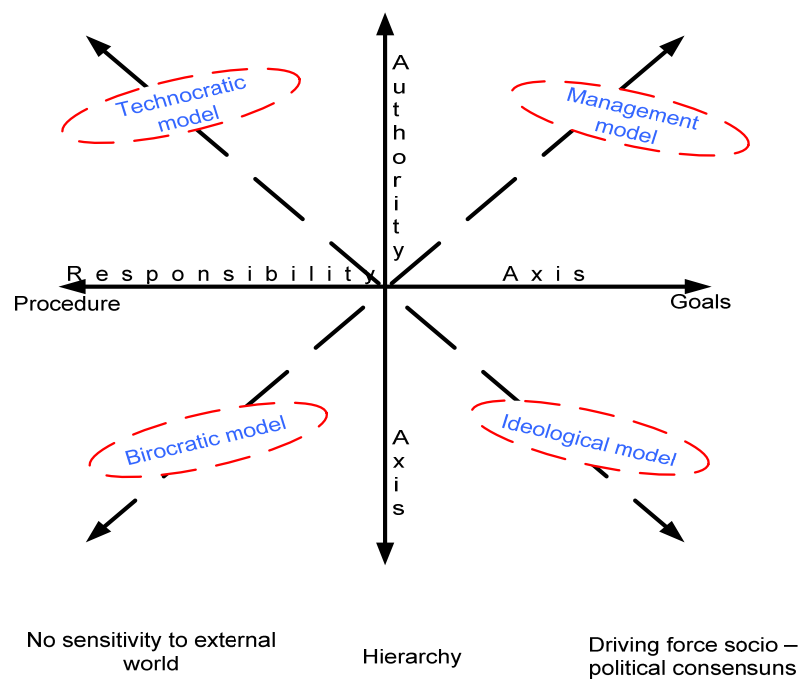

Figure 3: Traditional organisational models. Source: MARETOPE [3].

\section{Criteria of governing urban public transport}

The special problem of selecting an applicable governing model refers to the segmentation of urban transport. In order to increase the usage and efficiency of the urban public transport system it is necessary to study in more detail the factors that move or restrict the effects of this system. These are primarily the social and economic criteria of efficiency - the increased use of the urban public transport system and the improvement of the conditions of environmental quality or contribution to employment. In this group, one has to mention the accessibility, quality, availability and affordability of public transport services. An important role lies also within the criteria of financial and economic efficiency, especially concerning the internal cost efficiency and user-oriented offers. This complex assumes interconnected objectives and the functioning criteria of urban public transport. The current meeting of such objectives of the transport policy should be explained by a package of generic and locally specific historical factors. Indication of policy success lies within the usage of the urban public transport system, which is a composite indicator of numerous politically relevant criteria. The characteristics of the urban public transport system, articulated through the notions of share and quality, depend crucially on the package of the critical conditions of success. The majority of these critical conditions are divided into four groups - external, strategic, tactical and operative. External conditions do not belong under the authority of urban public 
transport management and therefore cannot be controlled - population, population density, population distribution, large incident gatherings and manifestations, etc. The objectives of urban public transport are under the influence of strategic factors, which are determined by various stakeholders, particularly national, regional and local authorities - political interests, a specific regulative of urban public transport, integrated public transport and urban development. The tactical level refers to the issue of how general objectives can reflect on the implementation of urban public transport services - organizational frames, financial frames, subsidies, public-private partnership and the symbiosis of urban public and other transport modes. The operative group of conditions contains the serving and performing of urban public transport services - diverse offers (bus, metro, tramway, etc.), the privileged position of urban public transport (the priority in using the infrastructure), traffic density (frequency, intensity), the integration of public transport (maps, logistics, routes) and marketing and public transport information technology [4].

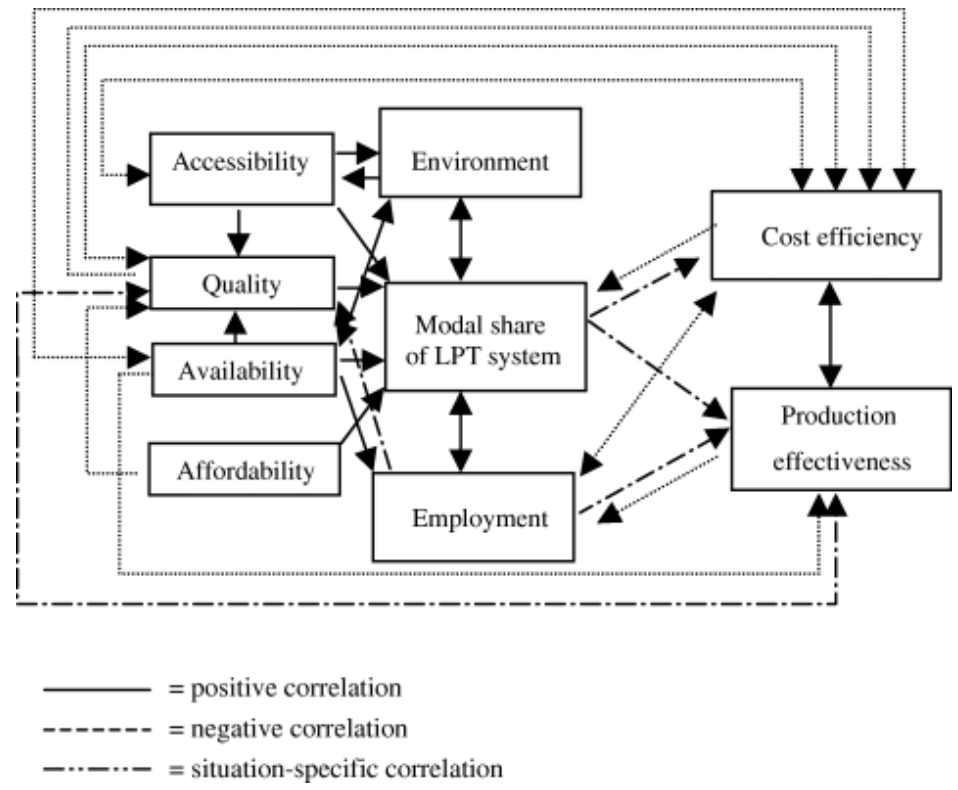

Figure 4: Interaction scheme of LPT objectives/criteria. Source: Van Egmond et al. [4].

\section{Applicable urban public transport model in Croatia}

In considering the applicable models and scenarios for the development of urban public transport in Croatia, the starting basis lies in evaluating the status of the levels of its establishment, regulation and organization. About 70 per cent of the population and about 80 per cent of the traffic are concentrated in the urban areas of Croatia; the regulation of this transport segment at a governmental level 
does not exist and the authority for managing urban transport has been delegated to the level of local authorities. The municipal authorities have no autonomy of action in the regulation of transport; there is a lack of integration within the segments of planning, monitoring, management and the controlling of urban transport and a large number of cities in Croatia have no organized urban public transport modes. In bigger towns, such as Zagreb, Split or Rijeka, the solving of urban transport issues, due to the negative impacts of uncontrolled growth in individual road transport on the quality of living, has become a question of the sustainability of further development. Whereas, in smaller towns and urban settlements the failure to organize this transport mode has made the realization of the basic rights of citizens to mobility and freedom of movement questionable.

The complexity of the problems regarding urban transport management is reflected in different, yet interdependent, influencing factors: economic, regarding the efficiency and effectiveness of the public transport system expressed as the value of transport effects and economic benefits, social, regarding the provision of public services and the principles of accessibility for all the citizens in all areas and ecological, regarding the provision of mobility which will not endanger environmental protection and the health of the people.

The sectors of demographic policy, urban planning policy and environmental protection have to be integrated into the strategic planning and urban transport policy. Besides which, the subsidiary objectives of sustainable development impose the implementation of the principles of integration, inter-modality and sustainability in the regulation and organization of urban transport. It is not possible to realize the required integration and implementation in the existing regulatory and organizational regime of urban transport in Croatia, since in the existing system of "deregulated" urban transport management, the public authorities at the local level have neither the authority, the autonomy, nor the competencies for such action. Therefore, the model assumes the regulatory organization of urban transport at all the decision-making levels - the state and local levels of the county and municipal authorities. The regulatory organization of urban transport, apart from the mentioned vertical coordination and crosssector integration, also assumes the horizontal coordination of the transport sector, particularly in the issues of the modal structure of urban transport (modal share). At the state level and local county level, it is necessary to organize the authorities for urban transport with a view to the strategic planning of transport development. It is also important to include the role of authority in the standardization of the minimal conditions of the construction, organization and regulatory levels of urban transport and other instruments in the realization of national and county strategic objectives, which principally or conditionally denote the segment of urban transport. In this context, these levels have to ensure the budget means for the implementation of the dictated conditions in urban transport.

The authority, according to the model for urban transport at the local level of a city, has an executive role regarding the strategic development and policymaking for urban public transport - the planning, regulation, organization and management of the urban public transport system. 


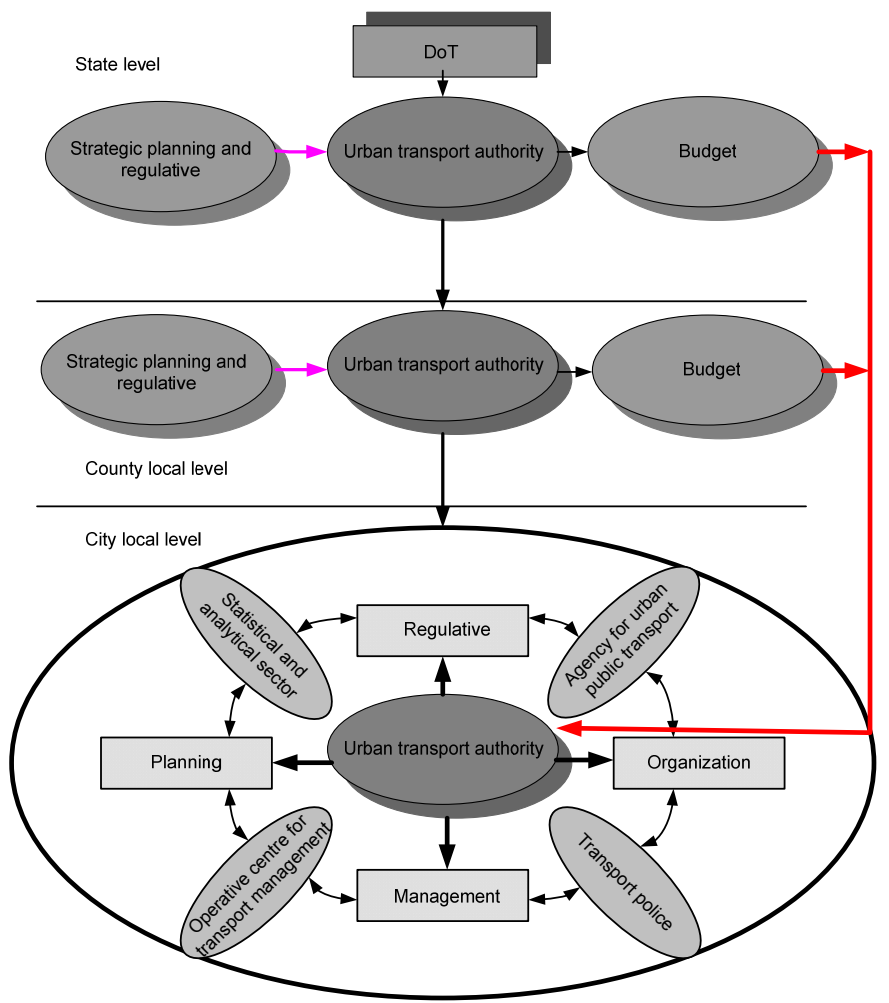

Figure 5: Model proposal for urban public transport system. Source: [6].

Therefore, the urban transport authority at this level has to have autonomy of action and the budget means. Recognizing the good practice of separating the regulatory and operative functions, the model of urban public transport assumes the establishing of an agency for urban public transport with the tasks of certification, licensing and concessions of operators in urban public transport and the contracting of all the outsourcing arrangements for the realization of the operational plans and programs in urban public transport. The organizational model of urban public transport should be based on the semi-market operational concept in order to ensure a balance between the economic interests and the uniformity of the public service offer and quality of service. For the requirements of monitoring and the management of urban transport as well as of public transport, the model foresees the establishment of a series of support units of urban transport entities - an operational centre for transport management, the statistical and analytical sector and the urban transport police. The public transport segment, as part of urban transport, should not be treated separately here and the model assumes that in these entities of planning, management and control, all the urban transport modes are uniformly represented and integrated [4-6]. 


\section{Public transport management}

Apart from regulatory, investment and fiscal aspects, transport management is one of the key areas of transport policy, which has marked social and economic effects - on the one hand in reducing the external costs of transport and on the other hand in the affirmation of intermodal transport and logistics. The social and economic benefits of implementing intelligent transport systems as a superstructure in transport engineering are expressed in the following:

- the reduction of transport congestion and waiting,

- the reduction of the travelling costs,

- an increase in safety,

- the reduction of harmful emissions and fuel consumption,

- an increase in efficiency of carriers,

- the improvement of the effectiveness of investments in the network infrastructure.

The implementation of the principles of integration, interoperability and sustainability in transport policy necessarily assume the implementation of ITS solutions in all phases of transport engineering - from planning, design and construction to organization and exploitation and in all the segments of the transport system - from the development of transport routes, vehicles and transport terminals to the transport management system. The social and economic efficiency of the transport system is not indicated by the technical elements of the transport network or by the volume of transport work only, nor is it expressed purely by the length and density of the transport routes or transport performance, but also through the qualitative aspects of transport demand management, which are articulated by transport safety and environmental protection and finally by spatial, demographic and economic cohesion of the region.

\section{Conclusions}

Solving the problems of public transport, especially in urban areas, directly correlates with numerous non-transport disciplines. Therefore, the wider themes of area (physical) planning, sustainable development and environmental issues are noted within the context of this paper. Problems in the integration of the objectives of the physical planning, environmental protection and mobility in transport policy are real both in the cities of the European Union, as well as in the cities of the transition countries. The models for the improvement of urban transport in the pilot projects already realised are analogously applicative at a regional level. This fact is of great importance for the regulatory harmonisation, strategic planning and policy of urban transport management in Croatia. Transport policy needs to show special sensitivity to solving the problems of urban transport management, so that in this sense, the combined instruments in cooperation with medical, social, and other departments should be used to influence the shift of the transport demand from individual to public transport, 
the prevention of unnecessary traffic by reducing the travelling distance, the use of IT technologies etc. An entire spectrum of strategic functions is usually developed for the agency at the level of metropolitan region, including; the development strategy of urban planning; the environmental protection strategy; road planning, including the supervision of private concession development; the transport management strategy; and the parking and road charging strategy. This fact is of great importance for regulatory harmonization, strategic planning and the policy of urban transport management in Croatia.

\section{References}

[1] S. Steiner. Elements of Transport Policy (in Croatia). University of Zagreb, Faculty of Transport and Traffic Sciences, Zagreb, p. 56; 2006.

[2] R. Macário. Managing and Assessing Regulatory Evolution in Local Public Transport Operations in Europe. Proc. Of the 7th Inter. Conf. "Competition and Ownership", Molde, Norway, June 25-28, 2001.

[3] Reference Framework and Harmonisation of Concepts. MARETOPE (D1), Project funded by the European Commission under the Competitive and Sustainable Growth programme, 2000.

[4] P. Van Egmond, P. Nijkamp, G. Vindigni, A comparative analysis of the performance of urban public transport systems in Europe. Int. Social Science Journal, 176, UNESCO, Blackwell Publishing Ltd., Oxford, pp. 136-147, 2003.

[5] J. Golubić, Z. Vogrin. Analysis of Harmful Emissions Generated by Road Traffic in the City of Zagreband Proposals of Measures. Transport Problems I, pp. 169-176, 2012.

[6] Z. Vogrin: Parametri razvitka javnog gradskog prometa, Master thesis, Faculty of traffic and transportation, Zagreb, 136, 2007.

[7] J. Vurdelja, Z. Vogrin. Daily Migrations of Citizens as a Transport Demand Factor. Proc. of 9th Inter. Scienc. Conf. "MOBILITA 04", eds. K. Bačova, Bratislava, pp. 39-46, 2004.

[8] Improved Structure and Organisation for Urban Transport Operations of Passengers in Europe. ISOTOPE, Project funded by the European Commission under the 4th Framework Programme, 1997.

[9] G. M. Karlaftis: Privatization, Regulation and Competition: A Thirty-Year Retrospective on Transit Efficiency. Presented at European Conf. of Ministers of Transport, Privatisation and Regulation of Urban Transit Systems, Round table 138, Joint OECD/ECMT Transport Research Centre, CEMT/OCDE/JTRC/TR(2006)7. 